\title{
Multiple Sklerozlu Bireylerde Enerji Koruma ve Zaman Yönetimi Eğitiminin Yorgunluğa ve Okupasyonel Performansa Etkisi
}

Effects of Energy Conservation and Time Management Training on Fatigue and Occupationa Performance in Individuals with Multiple Sclerosis

Gamze EKici ${ }^{1}$, Ege TEMIZKAN ${ }^{2}$, Elif PEKŞEN ${ }^{3}$

${ }_{1}^{1}$ Prof. Dr., Hacettepe Üniversitesi, Sağlık Bilimleri Fakültesi, Ergoterapi Bölümü, Ankara, Türkiye

${ }^{2}$ Uzm. Erg., Hacettepe Üniversitesi, Sağlık Bilimleri Fakültesi, Ergoterapi Bölümü, Ankara, Türkiye

${ }^{3}$ Erg., Hacettepe Üniversitesi, Sağlık Bilimleri Fakültesi, Ergoterapi Bölümü, Ankara, Türkiye

\section{ÖZ}

Amaç: Multiple Skleroz'da (MS) yorgunluk, bireyin rutin okupasyonlarını tamamlayamaması ile tanımlanan fiziksel ve mental enerji eksikliğidir. Bu çalışmanın amacı MS'de enerji koruma ve zaman yönetimi eğitiminin yorgunluğa ve oküpasyonel performansa etkisini incelemektir. Gereç ve Yöntem: Bireylere Yorgunluk Şiddet Ölçeği, Yorgunluk Etki Ölçeği (YEÖ), Kanada Aktivite Performansı Ölçümü uygulandı. Tüm bu değerlendirmeler eğitim öncesi ve sonrası olmak üzere 2 kez yapıldı. Bireylere toplam 10 seans enerji koruma ve zaman yönetimi eğitimi verildi. Sonuçlar: Çalışmaya yaş ortalaması $39,66 \pm 10,92$ yıl olan 15 kişi dahil edildi. Eğitim öncesi ve sonrası bulgular karşılaştırıldığında bireylerin yorgunluk şiddeti $(p=0.001)$, yorgunluğun etkilediği bilişsel alan $(p=0.001)$, sosyal alan $(p=0.003)$, fiziksel alan $(p=0.001)$ ve toplam YEÖ puanlarında $(p=0.001)$ azalma görüldü. Bireylerin okupasyonel performans $(p<0.001)$ ve memnuniyet $(p<0.001)$ değerlerinde ise istatistiksel olarak anlamlı artış görüldü. Tartışma: Enerji koruma ve zaman yönetimi eğitiminin MS'li bireylerin yorgunluk, okupasyonel performans ve memnuniyet üzerine olumlu etkileri olduğu görülmüştür. Bu nedenle MS'de enerji koruma ve zaman yönetimi eğitiminin müdahale programlarına dahil edilmesi yararlı olacaktır. Daha büyük örneklem gruplarının dahil edildiği, kontrollü ve takipli çalışmalara ihtiyaç vardır.

Anahtar kelimeler: Multipl skleroz; Zamanı yönetme; Yorgunluk; Ergoterapi

\section{ABSTRACT}

Purpose: Fatigue in Multiple Sclerosis (MS) is the lack of physical and mental energy, defined by the individual's inability to complete routine activities. The purpose of this study is to examine the effect of energy conservation and time-management training on fatigue and occupational performance with MS. Material and Methods: Fatigue Severity Scale, Fatigue Impact Scale (FIS) and Canadian Occupational Performance Measure were done before and after the training. Individuals received 10 sessions of energy conservation and time-management training. Results: 15 individuals with a mean age of $39.66 \pm 10.92$ years were included in the study. When the scores of before and after the training were compared, decreases were seen in terms of the fatigue severity $(p=0.001)$, cognitive domain affected by fatigue $(p=0.001)$, social area $(p=0.003)$, physical area $(p=0.001)$ and in total FIS $(p=0.001)$. There was a significant increase in occupational performance $(p<0.001)$ and satisfaction $(p<0.001)$ of individuals. Discussion: Energy conservation and time-management training have been found to have positive effects on fatigue and occupational performance in individuals with MS. So, it would be beneficial to include energy conservation and time-management training in intervention programs for MS. There is a need for controlled follow-up studies with larger sample groups.

Keywords: Multiple sclerosis; Time management; Fatigue; Occupational therapy 
Multiple Skleroz (MS), merkezi sinir sisteminde meydana gelen kronik nörodejeneratif bir hastalıktır (De-Bernardi-Ojuel, Torres-Collado ve García-de-la-Hera, 2021). Travmaya bağlı olmaksızın nörolojik yeti kaybına neden olan hastalıklar arasında yer alan MS'in dünyada 1,12,5 milyon kişiyi etkilediği tahmin edilmektedir (Gilmour, Ramage-Morin ve Wong, 2018). Türkiye'de kesin olmamakla birlikte görülme sıklığı 40/100000 civarındadır (Börü, Duman, Kulualp ve ark., 2018). Kadınlarda erkeklere oranla 2 kat daha fazla görüldüğü bildirilmektedir (Patel, SirDeshpande, Desai ve ark., 2019). MS'li bireylerde; denge sorunları, ağrı, kognitif bozukluk, depresyon ve yorgunluk gibi belirtiler görülebilir (Barin, Salmen, Disanto ve ark., 2018).

MS'te yorgunluk, birey ya da bakım vereni tarafından algılanan ve bireyin rutin okupasyonlarını tamamlayamaması ile belirlenen subjektif bir fiziksel ve mental enerji eksikliğidir (Ayache ve Chalah, 2017). MS'te yorgunluk bireylerin fiziksel ve mental fonksiyonlarını, okupasyonel performanslarını, istihdam edilebilirlik düzeylerini ve toplumsal katılımlarını kısıtlayabilir (Ayache ve ark., 2017; van Zanten, Douglas ve Ntoumanis, 2021). Yorgunluk, MS'li bireyde kuvvet ve enduransı olumsuz etkilediğinden bireyin çeşitli günlük yaşam aktivitelerini (GYA) yapmakta zorluk yaşamasına sebep olur (van Zanten ve ark. 2021). Hastalığa bağlı oluşan mobilite kaybı, bireyin GYA'larını yerine getirme yeteneğini azaltmakta ve başkalarına bağımlılığı artırmaktadır. Hastalık ilerledikçe bireyin öz-bakım kapasitesi azalmakta ve aile üyelerinin yardımına intiyaç duyulmaktadır. Dolayısıyla MS, bireyi fiziksel, psikolojik ve sosyal olarak etkilemektedir (García Jalón, Lennon, Peoples ve ark., 2013). Okupasyonel performans; kültürel olarak kişinin yaşına ve cinsiyetine uygun, kişi için anlamlı işi seçebilme, organize edebilme ve bu işleri yapabilme yeteneği olarak tanımlanabilir (de Heredia-Torres, Huertas-Hoyas, Sánchez-Camarero ve ark., 2020). MS'te GYA'larındaki limitasyonların kişisel bağımsızlık, yaşam kalitesi, bireylerin sosyal rolleri ve ailelerin refahına olumsuz etkisi vardır (Hyarat, Subih, Rayan ve ark., 2019).

MS'li bireylerde yorgunluğun, bireyin günlük yaşam performansı üzerine olumsuz etkisini azaltmak için birçok sağlık profesyoneli tarafından çeşitli müdahaleler uygulanmaktadır (DeBernardi-Ojuel ve ark., 2021; O'Loughlin, Hourihan, Chataway ve ark., 2017). Bu müdahaleler içerisinde en çok tercih edilen yöntemler; kardiyovasküler ve kuvvetlendirme egzersizleri (Kalb, Brown, Coote ve ark., 2020), yoga (Green, Huynh, Broussard ve ark., bilişsel-davranışsal terapi (van den Akker, Beckerman, Collette ve ark., 2016), enerji koruma eğitimi (Blikman, van Meeteren, Twisk ve ark., 2019; Quinn ve Hynes, 2020; Salomè, Sasso D'Elia ve ark., 2019) ve zaman yönetimi eğitimidir (Yu ve Mathiowetz, 2014). Enerji koruma ve zaman yönetimi eğitimleri; hem yorgunluk meydana gelmeden önce yorgunluğu önlemeyi hedeflemesi, hem de günlük zaman yönetimini içermesi ve bunlara ek olarak uygulanması kolay ve maliyetinin düşük olması ile öne çıkmaktadır (De-Bernardi-Ojuel ve ark., 2021; Yu ve ark., 2014). Enerji koruma teknikleri, kronik hastalığı olan kişilerde yorgunluk yönetimi için uygulanan farmakolojik olmayan bir müdahaledir. MS hastaları için ise okupasyonlarını nasıl düzenleyeceklerini, nasıl analiz edeceklerini ve yorgunlukla nasıl başa çıkacaklarını öğreten bir eğitimdir (Salomè ve ark., 2019). Zaman yönetimi, hedeflere ulaşmada önemli bir kaynak olan zamanı verimli kullanma çabasıdır (Audulv, Hutchinson, Warner ve ark., 2021). MS'li birey, önceliklerini sıraya koyarak okupasyonlarını planlaması, zaman yönetimi ve yaşamını organize ederek enerjisini kullanması konularında motive edilmelidir (Audulv ve ark., 2021; Giovannoni, Butzkueven, Dhib-Jalbut ve ark., 2016).

Günümüzde yorgunluk sorunu yaşayan $\mathrm{MS}$ 'li bireylere yönelik çalışmalara ilgi artmasına rağmen, bireye özgü zaman yönetimi ve enerji koruma teknikleri gibi müdahalelerin bireyin okupasyonel performansını oluşturan kendine bakım, serbest zaman ve üretkenlik alanlarındaki performans ve memnuniyetlerine olan etkisini inceleyen herhangi bir çalışmaya rastlanmamıştır.

$\mathrm{Bu}$ çalışma MS'li bireylerde enerji koruma ve zaman yönetimi eğitimlerinin yorgunluğa ve okupasyonel performansa etkisini incelemek amacıyla yapılmıştır.

\section{GEREÇ VE YÖNTEM}

Bu çalışma Hacettepe Üniversitesi, Sağlık Bilimleri Fakültesi, Ergoterapi Bölümü ve Ankara Multiple Skleroz Derneği'nin işbirliğiyle gerçekleştirilmiştir. Hacettepe Üniversitesi Girişimsel Olmayan Klinik Araştırmalar Etik Kurulu'nca incelemeye alınarak, GO 18/405 numarası ile etik olarak uygun bulunmuştur.

Çalışmaya MS tanısı almış, 18-65 yaş aralığında, okur-yazar, remisyon döneminde, Yorgunluk Şiddet Ölçeği'nden (YŞÖ) 4 ve üzeri puan alan gönüllü bireyler dahil edilmiştir. Çalışma başlangıcından önce ya da sonra alevlenme ya da aktif hastalık dönemine giren 
bireyler ise çalışma dışı bırakılmıştır. Tüm katılımcılara çalışma hakkında bilgi verilip, kabul edenlere çalışmanın amaç ve yöntemlerini belirten aydınlatılmış onam formu imzalatılmıştır.

Çalışmanın başlangıcında, 21 kişi dahil etme ve hariç bırakma kriterlerine göre çalışmaya alınmıştır. Bireylerin atak geçirme; $(n=1)$, gidişgeliş problemi $(n=2)$ ve nedeni bilinmeyen şekilde eğitimi yarıda bırakmaları $(n=3)$ sebeplerinden dolayı çalışma 15 kişiyle tamamlanmıştır. Katılımcı alım süreci ile ilgili ayrıntılı bilgi, akış haritasında (Şekil 1) bulunmaktadır.

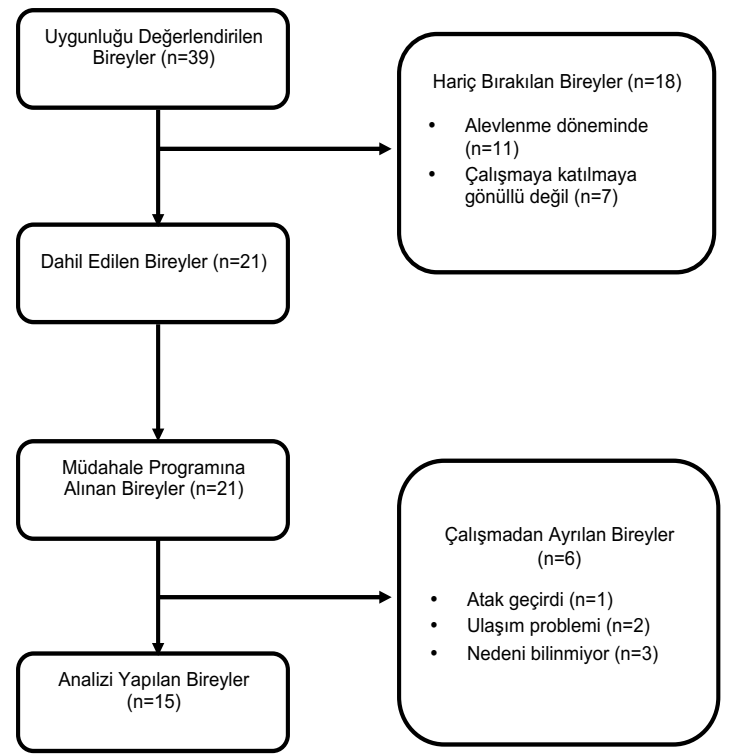

Şekil 1. Katılımcıların dahil edilmesine dair akış haritası

\section{Veri Toplama Araçları}

Bireylerin yaş (yıl), boy $(\mathrm{cm})$, kilo $(\mathrm{kg})$, vücut kütle indeksi (vki) $\left(\mathrm{kg} / \mathrm{m}^{2}\right)$, eğitim durumu (yıl), cinsiyet, çalışma durumu, kronik hastalıkların varlığına yönelik bilgileri sorgulanarak kaydedilmiştir. Ayrıca, katılımcılara müdahale öncesi ve sonrası olmak üzere 2 kez "Yorgunluk Şiddet Ölçeği", "Yorgunluk Etki Ölçeği" ve "Kanada Aktivite Performans Ölçümü" uygulanmıştır.

Yorgunluk Şiddet Ölçeği (YŞÖ): Bu ölçek bireyin son bir aydaki yorgunluk durumunu değerlendirir. Dokuz sorudan oluşur. Alınan cevaplar 1-7 arasında puanlanır ve en yüksek puan 63'tür. Toplam puanın 9'a bölünmesi ile sonuç elde edilir. 4 puan ve üzerinde olması yorgunluğu gösterir. Ölçeğin Türkçe geçerlilik ve güvenilirlik versiyonu Armutlu ve arkadaşları tarafından yapılmıştır (Armutlu, Korkmaz, Keser ve ark., 2007).

Yorgunluk Etki Ölçeği (YEÖ): Yorgunluğun MS'li bireylerin mental ve genel sağlık durumunu nasıl etkilediğini değerlendirmek için kullanılan bir ölçektir. Son 1 aydaki yorgunluk durumunu değerlendirir. 10 soru bilişsel durumu, 10 soru fiziksel durumu ve 20 soru sosyal durumu değerlendirmek üzere toplam 40 sorudan oluşur. Her soru 0 (problem yok) 4 (maksimum problem) puan arasında puanlanmaktadır. En yüksek puan 160'tır. Yüksek skor yorgunluğu belirtir. Ölçeğin Türkçe geçerlilik ve güvenilirlik versiyonu Armutlu ve arkadaşları tarafından yapılmıştır (Armutlu, Keser, Korkmaz ve ark., 2007).

Kanada Aktivite Performans Ölçümü (KAPÖ): Okupasyonel performansı ve memnuniyet düzeyini değerlendirmek için kullanılan bir ölçektir. Öncelikle bireylerden kendine bakım, iş ve üretkenlik ve serbest zaman okupasyonları alanlarında yaşadıkları problemleri belirlemeleri istenir. Daha sonra belirledikleri her okupasyona likert skalasına göre 1-10 arasında bir önem değeri vermesi istenir (1-Hiç önemli değil, 10-çok önemli). Sonraki aşamada kendileri için en önemli en az 1, en fazla 5 okupasyonu seçmeleri ve bu okupasyonların her biri için yine likert skalasına göre 1-10 arasında performans ve memnuniyet puanı vermeleri istenir. Elde edilen performans ve memnuniyet puanları toplanarak bireyin belirttiği okupasyon sayısına bölünür ve toplam performans ve memnuniyet puanları elde edilir (Carswell, McColl, Baptiste ve ark., 2004; Law, Baptiste, Carswell ve ark., 1998). KAPÖ'nün Türkçe geçerlilik ve güvenilirliği multiple sklerozlu bireylerde gösterilmiştir (Torpil, EkiciÇağlar ve Bumin, 2018).

\section{Müdahale Programı}

Katılımcılara haftada 2 kez 5 hafta olmak üzere toplam 10 seans enerji koruma ve zaman yönetimi eğitimi verilmiştir.

Zaman yönetimi: Bireyin günlük yaşamdaki okupasyonları yerine getirirken kişinin planlı ve önceliklerini belirleyip, mevcut enerjisini optimum seviyede kullanmasını amaçlar (Audulv ve ark., 2021). Enerji koruma eğitimi: Yorgunluğa neden olan kronik hastalıklara sahip olan bireyler için Packer ve arkadaşları tarafından geliştirilmiştir (Blikman, van Meeteren, Twisk ve ark., 2017; Packer, 1995). Bu eğitim; dinlenmenin önemi, enerjiyi depolama ve kullanma, vücut mekaniğinin uygun kullanımı, okupasyonların organize edilmesi, yardımcı teknoloji kullanımı, öncelikleri ve standartları ayarlama, günlük yaşamdaki dengeyi sağlama gibi stratejileri içerir.

Eğitim öncelikleri haftalara göre şu şekilde belirlenmiştir.

1. hafta: Kişinin 1 gününü değerlendirmek, önceliklerini belirlemek ve zamanı etkili kullanma yollarının anlatılmasını (kendini tanıma, sınırlarını bilme, düzen 
kurma, hedef belirleme, plan yapma, iradeyi koruma-plana sadık kalma, iç muhasebeye dikkat etme, ve kişiye yönelik tavsiyeler) içerir.

2. hafta: Vücut mekaniği, postür, ergonomik prensipler, yapılması ve yapılmaması gerekenler,

3. hafta: Günlük oküpasyonel denge ve zaman yönetimi ile ilgili uygulamalar ve öneriler,

4. hafta: Günlük yaşamı kolaylaştırabilecek yardımcı araçların tanıtımı

5. hafta: Görsel video ve sunum ile önceki haftaları tekrar etme, geri bildirim sağlanması şeklindedir.

\section{Istatistiksel Analiz}

İstatistiksel analizlerde SPSS v.26 istatistik programı kullanımıştır. Bireylerin sosyodemografik özellikleri, cinsiyet, eğitim, medeni durum, meslek, kronik hastalıklar, çalışma süreleri, yaş ve vücut kütle indeksi gibi tanımlayıcı verilerde uygunluğuna göre frekans ve/veya ortalama \pm Standart Sapma $(\mathrm{X} \pm \mathrm{SS})$ değerleri verilmiştir. Yorgunluk, okupasyonel performansı ve memnuniyeti için tedavi öncesi ve 10 seans sonra elde edilen veriler Wilcoxon Eşleştirilmiş Test kullanılarak değerlendirilmiştir. Müdahalenin etkililiğinin analiz edilmesi amacı ile Yorgunluk Etki Ölçeği alt parametre skorları, Yorgunluk Şiddet Ölçeği toplam skoru ve Kanada Aktivite Performans Ölçeği Ortalama Performans ve Memnuniyet skorlarında müdahale öncesi ve sonrası etki değerleri hesaplanmıştır. Etki değerlerinin hesaplanması ve yorumlanmasında; Fritz, Morris ve Richler tarafından (Fritz, Morris ve Richler, 2012) ortaya koyulan yönergeler esas alınmıştır. Etki değeri analizi sonuçları; etki değerinin 0,5 ya da daha büyük olması durumunda "Kuvvetli Etki", 0,5 ile 0,3 arasında olması durumunda "Orta Kuvvette Etki" ve 0,3 ile 0,5 arasında olması durumunda "Zayıf Etki" olarak yorumlanmıştır (Fritz ve ark., 2012). İstatistiksel anlamlılık düzeyi $p<0,05$ olarak kabul edilmiştir.

\section{SONUÇLAR}

Çalışmamız yaş ortalaması 39,6 \pm 10,9 yıl olan 10 kadın, 5 erkek katılımcı ile tamamlanmıştır. Sosyodemografik bilgiler Tablo 1'de verilmiştir. Eğitim öncesi ve sonrasında ölçülen değerlendirmelerin istatistiksel sonuçları Tablo 2'de sunulmuştur.

Bireylerin YŞÖ sonuçlarına bakıldığında eğitim öncesi ortalama değerlerin $(5,21 \pm 0,75)$ eğitim sonrasında $(4,01 \pm 1,03)$ istatistiksel olarak anlamlı olarak ( $p=0,001)$ azaldığı görülmüştür. Yorgunluğun etkilediği bilişsel alan $(p=0,001)$, sosyal alan $(p=0,003)$, fiziksel alan $(p=0,001)$ ve toplam YEÖ puanlarında $(p=0,001)$ da istatistiksel olarak anlamlı azalmalar görülmüştür (Tablo 2). Fakat 15 bireyin 10 unda yorgunluğun etkilediği alanlardan fiziksel, sosyal, bilişsel alanların hepsinde azalma görülürken 5 bireyde ise fiziksel ve bilişsel alanlarda azalma olmuş, sosyal alanda azalma olmamıştır. Bireylerin okupasyonel performans $(p<0,001)$ ve memnuniyet $(p<0,001)$ değerlerinde ise istatistiksel olarak anlamlı artışlar görülmüştür (Tablo 3).

Müdahale öncesi ve sonrası değerlendirme sonuçları arasındaki farklardaki etki büyüklüğü incelendiğinde, yorgunluk şiddeti $(0,62)$, yorgunluğun etkilediği bilişsel alan $(0,59)$, sosyal alan $(0,54)$, fiziksel alan $(0,60)$, toplam yorgunluk etkisi $(0,62)$, okupasyonel performans $(0,67)$ ve bu performanstan duyulan memnuniyette $(0,63)$ kuvvetli etki tespit edilmiştir.

Tablo 1. Bireylerin sosyo-demografik bilgileri

\begin{tabular}{|c|c|c|}
\hline & & n (\%) \\
\hline \multirow[t]{2}{*}{ Cinsiyet } & Kadın & $10(66,7)$ \\
\hline & Erkek & $5(33,3)$ \\
\hline \multirow[t]{2}{*}{ Medeni Durum } & Bekar & $8(53,3)$ \\
\hline & Evli & $7(46,7)$ \\
\hline \multirow[t]{5}{*}{ Birlikte yaşadığı kişiler } & Yalnız & $2(13,3)$ \\
\hline & Eşi ile birlikte & $3(20,0)$ \\
\hline & Eş ve çocuklar & $7(46,7)$ \\
\hline & Anne ve baba & $2(13,3)$ \\
\hline & Diğer & $1(6,7)$ \\
\hline \multirow[t]{2}{*}{ Çalışma durumu } & Çalışıyor & $7(46,7)$ \\
\hline & Çalışmıyor & $8(53,3)$ \\
\hline Başka kronik hastalıkların & Yok & $13(86,7)$ \\
\hline \multirow[t]{2}{*}{ olması } & Var & $2(13,3)$ \\
\hline & Min - Max & $X \pm S S$ \\
\hline Yaş (yıl) & $26-58$ & $39.6 \pm 10.9$ \\
\hline VKİ $\left(\mathrm{kg} / \mathrm{m}^{2}\right)$ & $19,8-29.7$ & $25.1 \pm 3.33$ \\
\hline Eğitim (yıl) & $8-17$ & $12,0 \pm 2.93$ \\
\hline
\end{tabular}


Tablo 2. Bireylerin eğitim öncesi ve sonrası yorgunluk durumlarının karşılaştırılması

\begin{tabular}{|c|c|c|c|c|c|}
\hline & & Eğitim Öncesi & Eğitim Sonrası & & \\
\hline & & $X \pm S S$ & $X \pm S S$ & $z$ & $p$ \\
\hline Yorg & < SSiddet Ölçeği & $5,21 \pm 0.75$ & $4,01 \pm 1,03$ & $-3,411$ & $0.001^{*}$ \\
\hline Yorgunluk & Kognitif Yorgunluk & $17,00 \pm 3,60$ & $13,33 \pm 2,94$ & $-3,277$ & $0.001^{*}$ \\
\hline Etki Ölçeği & Fiziksel Yorgunluk & $20,26 \pm 4,13$ & $14,73 \pm 4,13$ & $-3,304$ & $0.001^{*}$ \\
\hline & Sosyal Yorgunluk & $33,53 \pm 25,65$ & $27,400 \pm 4,82$ & $-2,988$ & $0.003^{*}$ \\
\hline & Toplam & $70,80 \pm 10,54$ & $56,13 \pm 10,90$ & $-3,409$ & $0.001^{*}$ \\
\hline
\end{tabular}

${ }^{*} p<0,05$

Tablo 3. Bireylerin eğitim öncesi ve sonrası okupasyonel performans ve memnuniyet puanlarının karşılaştırılması

\begin{tabular}{|c|c|c|c|c|c|}
\hline & & \multicolumn{2}{|c|}{ Eğitimi Öncesi } & \multicolumn{2}{|c|}{ Eğitimi Sonrası } \\
\hline & & $\begin{array}{l}\text { Performans } \\
\text { Puanı }\end{array}$ & $\begin{array}{c}\text { Memnuniyet } \\
\text { Puanı }\end{array}$ & $\begin{array}{l}\text { Performans } \\
\text { Puanı }\end{array}$ & $\begin{array}{c}\text { Memnuniyet } \\
\text { Puanı }\end{array}$ \\
\hline \multirow{15}{*}{$\begin{array}{l}\text { Kendine } \\
\text { Bakım }\end{array}$} & Vaka 1 & 7 & 7 & 9 & 9 \\
\hline & Vaka 2 & 6 & 1 & 7 & 5 \\
\hline & Vaka 3 & 6 & 1 & 7 & 1 \\
\hline & Vaka 4 & - & - & - & - \\
\hline & Vaka 5 & 7 & 3 & 9 & 7 \\
\hline & Vaka 6 & - & - & - & - \\
\hline & Vaka 7 & - & - & - & - \\
\hline & Vaka 8 & 5 & 1 & 7 & 3 \\
\hline & Vaka 9 & - & - & - & - \\
\hline & Vaka 10 & - & - & - & - \\
\hline & Vaka 11 & 7 & 3 & 9 & 8 \\
\hline & Vaka 12 & 5 & 1 & 6 & 3 \\
\hline & Vaka 13 & - & - & - & - \\
\hline & Vaka 14 & 4 & 5 & 6 & 7 \\
\hline & Vaka 15 & 7 & 4 & 9 & 6 \\
\hline \multirow[t]{15}{*}{ Üretkenlik } & Vaka 1 & - & - & - & - \\
\hline & Vaka 2 & 2 & 1 & 5 & 7 \\
\hline & Vaka 3 & 7 & 1 & 8 & 4 \\
\hline & Vaka 4 & - & - & - & - \\
\hline & Vaka 5 & - & - & - & - \\
\hline & Vaka 6 & 2 & 2 & 3 & 2 \\
\hline & Vaka 7 & - & - & - & - \\
\hline & Vaka 8 & - & - & - & - \\
\hline & Vaka 9 & - & - & - & - \\
\hline & Vaka 10 & - & - & - & - \\
\hline & Vaka 11 & - & - & - & - \\
\hline & Vaka 12 & 3 & 1 & 6 & 2 \\
\hline & Vaka 13 & - & - & - & - \\
\hline & Vaka 14 & 5 & 6 & 7 & 8 \\
\hline & Vaka 15 & 7 & 8 & 9 & 9 \\
\hline \multirow{16}{*}{$\begin{array}{l}\text { Serbest } \\
\text { Zaman }\end{array}$} & Vaka 1 & 5 & 1 & 7 & 5 \\
\hline & Vaka 2 & - & - & - & - \\
\hline & Vaka 3 & 6 & 1 & 9 & 3 \\
\hline & Vaka 4 & 2 & 1 & 4 & 4 \\
\hline & Vaka 5 & 4 & 2 & 6 & 3 \\
\hline & Vaka 6 & 5 & 3 & 6 & 5 \\
\hline & Vaka 7 & 4 & 5 & 6 & 6 \\
\hline & Vaka 8 & 1 & 2 & 3 & 3 \\
\hline & Vaka 9 & 6 & 4 & 8 & 5 \\
\hline & Vaka 10 & 5 & 1 & 8 & 3 \\
\hline & Vaka 11 & 3 & 1 & 5 & 2 \\
\hline & Vaka 12 & - & - & - & - \\
\hline & Vaka 13 & 2 & 5 & 4 & 8 \\
\hline & Vaka 14 & 6 & 4 & 8 & 6 \\
\hline & Vaka 15 & 7 & 4 & 9 & 6 \\
\hline & & $\begin{array}{l}\text { Eğitim öncesi } \\
\quad X \pm S S\end{array}$ & $\begin{array}{l}\text { Eğitim sonrası } \\
\quad X \pm S S\end{array}$ & $z$ & $p$ \\
\hline \multirow[t]{2}{*}{ TOPLAM } & Performans & $3,86 \pm 1,45$ & $6,26 \pm 1,33$ & $-3,689$ & $0.00001^{*}$ \\
\hline & Memnuniyet & $2,40 \pm 1,45$ & $5,00 \pm 1,55$ & $-3,501$ & $0.00001^{*}$ \\
\hline
\end{tabular}




\section{TARTIŞMA}

Bu çalışmada, MS'li bireylerde enerji koruma ve zaman yönetimi eğitiminin yorgunluğa ve okupasyonel performansına olan etkisinin incelenmesi amaçlanmıştır. Bulgular incelendiğinde, bireylerin yorgunluk puanlarında azalma, okupasyonel performansında ve memnuniyetinde artış meydana geldiği tespit edilmiştir.

MS'li bireylerde eklem enerji koruma tekniklerinin yorgunluğu azaltmada zayıf etkiye sahip olduğu, bildirilmiştir (Blikman ve ark., 2017). Ek olarak, Sauter ve ark. tarafından 2007'de yapılan çalışmada, enerji koruma eğitiminin MS'li bireylerde yalnızca yorgunluk şiddetinde ve psikolojik yorgunlukta anlamlı gelişmeler sağlayabildiği ifade edilmiştir. Kos ve ark. tarafından 2016 yılında gerçekleştirilen çalışmada, eklem enerji koruma teknikleri ve zaman yönetimi yaklaşımlarının bir arada uygulanması ile MS'li bireylerde yorgunluğun anlamlı bir şekilde azaltılabileceği önerilmiştir (Kos, Duportail, Meirte ve ark., 2016). Çalışmamızda MS'li bireylere enerji koruma ve zaman yönetimi eğitimi birlikte verilmiş; yorgunluk şiddeti ve etkisinin istatistiksel olarak anlamlı bir şekilde ve kuvvetli etki değeri ile azaldığı tespit edilmiştir.

MS'li bireylerde okupasyonel performansın artırıması için yorgunluğun yönetimi ile ilgili yaklaşımlara intiyaç olduğu bilinmektedir. Fakat, planlanacak çalışmaların yapısı, süresi ve müdahale sıklığı konusunda literatürde bir fikir birliği bulunmamaktadır (Kos ve ark., 2016; Yu ve ark., 2014). Kidd ve ark. tarafından 2017 yılında MS'li bireylerde öz-yeterlilik çalışmalarının okupasyonel performansı ve fonksiyonellik seviyesini artırmada etkili olduğu ifade edilmiştir (Kidd, Carey, Mold ve ark., 2017). Bu çalışmalar kapsamında enerji koruma teknikleri, zaman yönetimi stratejileri, kişi merkezli okupasyonel adaptasyon önerileri ve kişiselleştirilmiş okupasyonel denge kurma çalışmaları yer almaktadır (Salomè ve ark., 2019). Çalışmamızda kullanılan müdahale yöntemi, bu özelliklerin ve parametrelerin birçoğunu içermektedir. Katılımcıların okupasyonel performansları ve bundan memnuniyetlerinin istatistiksel olarak anlamlı bir şekilde ve yüksek etki değeri ile artmış olması, kullanılan müdahale yönteminin kapsamlılığı ve fonksiyonel çıktılara odaklanmış olması ile açıklanabilir.

Bu çalışmada uygulanan müdahale yöntemi, kişi merkezli uygulama prensipleri ile uyum içerisinde planlanmış ve gerçekleştirilmiştir. Ek olarak, kapsamlı ve fonksiyonel çıktılara yönelik müdahale programı sayesinde okupasyonel performansta artış saptanmıştır. Fakat yorgunluk şiddeti, etkili ve okupasyonel performansta sağlanan artışların uzun dönemde ne kadar korunduğunun tespit edilmesi için takip yapılmamıştır. Çalışmamızda bir kontrol grubu yer almamaktadır. Ancak, müdahalenin etkileri istatistiksel anlamlılık seviyesinin yanı sıra etki değerleri ile de yorumlanmıştır. Çalışmamızın bu kısıtıııklarının yanı sıra, müdahale süreci boyunca MS'li bireylerin ulaşım problemleri, hava koşulları ve ani gelişen ataklardan dolayı planlanan seans düzenine uyum göstermekte zorluk yaşadıkları tespit edilmiştir. Bu nedenle araştırmacılar tarafından daha esnek ve değişikliklere açık bir müdahale planı yaklaşımı benimsenmiştir.

Çalışmamız enerji koruma ve zaman yönetimi eğitimlerinin yorgunluğa ve okupasyonel performansa olan etkilerinin incelendiği spesifik bir çalışmadır. Enerji koruma ve zaman yönetimi eğitiminin yorgunluk, okupasyonel performans ve memnuniyet üzerine olumlu etkileri olduğu tespit edilmiştir. Bu nedenle MS'de en önemli problemlerden olan yorgunluğun azaltılmasında, tedavi programlarının etkinliğinin artırımasında ve MS'li bireylerin okupasyonel performanslarının artırımasında kişiselleştirilmiş enerji koruma ve zaman yönetimi eğitiminin müdahale programlarına dahil edilmesi faydalı olacaktır. İleri çalışmalarda, kişiselleştirilmiş enerji koruma ve zaman yönetimi eğitimlerinin daha büyük örneklem gruplarında, uzun dönem takipli, randomize kontrollü bir çalışma deseni içerisinde incelenmesi gereklidir.

\section{Araştırmacıların Katkı Oranı}

Gamze Ekici: Fikir, dizayn, raporlama

Ege Temizkan: Veri analizi, raporlama

Elif Pekşen: Veri toplama, veri analizi, raporlama

\section{Çıkar Çatışması Beyanı}

Yazarlar arasında çıkar çatışması bulunmamaktadır.

\section{Destek/Teşekkür}

Çalışma sırasında hiçbir kurum ya da kişiden finansal destek alınmamıştır. Çalışmaya katımayı gönüllü olarak kabul eden ve destekleyen katılımcılara tüm yazarlar teşekkür eder.

\section{Kaynaklar}

Armutlu, K., Keser, İ., Korkmaz, N., Akbıyık, D. İ., Sümbüloğlu, V., Güney, Z. ve ark. (2007). Psychometric study of Turkish version of Fatigue Impact Scale in multiple sclerosis patients. J Neurol Sci, 255(1-2), 64-68. https://doi.org/10.1016/j.jns.2007.01.073

Armutlu, K., Korkmaz, N. C., Keser, I., Sumbuloglu, V., Akbiyik, D. I., Guney, Z. ve ark. (2007). The validity and reliability of the 
Fatigue Severity Scale in Turkish multiple sclerosis patients. Int J Rehabil Res, 30(1), 81-85. https://doi.org/10.1097/MRR.0b013e3280146ec4

Audulv, Å., Hutchinson, S., Warner, G., Kephart, G., Versnel, J., \& Packer, T. L. (2021). Managing everyday life: Self-management strategies people use to live well with neurological conditions. Patient Educ Couns, 104(2),

413-421. https://doi.org/10.1016/j.pec.2020.07.025

Ayache, S. S., \& Chalah, M. A. (2017). Fatigue in multiple sclerosis-insights into evaluation and management. Clin Neurophysiol, 47(2), 139-171. https://doi.org/10.1016/j.neucli.2017.02.004

Barin, L., Salmen, A., Disanto, G., Babačić, H., Calabrese, P., Chan, A. ve ark. (2018). The disease burden of multiple sclerosis from the individual and population perspective: which symptoms matter most? Mult Scler Relat Disord, 25, 112-121. https://doi.org/10.1016/j.msard.2018.07.013

Blikman, L. J. M., van Meeteren, J., Twisk, J. W. R., de Laat, F. A. J., de Groot, V., Beckerman, H. ve ark. (2019). Energy Conservation Management for People With Multiple Sclerosis-Related Fatigue: Who Benefits? Am J Occup Ther, 73(4), 7304205040p1-7304205040p9. https://doi.org/10.5014/ajot.2019.032474

Blikman, L. J. M., van Meeteren, J., Twisk, J. W. R., de Laat, F. A. J., de Groot, V., Beckerman, H. ve ark. (2017). Effectiveness of energy conservation management on fatigue and participation in multiple sclerosis: A randomized controlled trial. Mult Scler J, 23(11), 15271541. https://doi.org/10.1177/1352458517702751

Börü, Ü. T., Duman, A., Kulualp, A. Ş., Güler, N., Taşdemir, M., Yılmaz, Ü. ve ark. (2018). Multiple sclerosis prevalence study: The comparison of 3 coastal cities, located in the black sea and mediterranean regions of Turkey. Medicine (Baltimore), 97(42). https://doi.org/10.1097/MD.0000000000012856

Carswell, A., McColl, M. A., Baptiste, S., Law, M., Polatajko, H., \& Pollock, N. (2004). The Canadian Occupational Performance Measure: a research and clinical literature review. Can J Occup Ther, 71(4), 210-222. https://doi.org/10.1177/000841740407100406

De-Bernardi-Ojuel, L., Torres-Collado, L., \& García-de-laHera, M. (2021). Occupational therapy interventions in adults with multiple sclerosis or amyotrophic lateral sclerosis: a scoping review. Int J Environ Res Public Health, $18(4), \quad 1432$. https://doi.org/10.3390/ijerph18041432

de Heredia-Torres, M. P., Huertas-Hoyas, E., SánchezCamarero, C., Máximo-Bocanegra, N., Alegre-Ayala, J., Sanchez-Herrera-Baeza, P. ve ark. (2020). Occupational performance in multiple sclerosis and its relationship with quality of life and fatigue. Eur J Phys Rehabil Med, 56(2), 148-154. https://doi.org/10.23736/s1973-9087.20.05914-6

Fritz, C. O., Morris, P. E., \& Richler, J. J. (2012). Effect size estimates: current use, calculations, and interpretation. J Exp Psychol Gen, 141(1), 2-18. https://doi.org/10.1037/a0024338

García Jalón, E. G., Lennon, S., Peoples, L., Murphy, S., \& Lowe-Strong, A. (2013). Energy conservation for fatigue management in multiple sclerosis: a pilot randomized controlled trial. Clin Rehabil, 27(1), 63-74. https://doi.org/10.1177/0269215512446495

Gilmour, H., Ramage-Morin, P. L., \& Wong, S. L. (2018). Multiple sclerosis: Prevalence and impact. Heal Reports, 29(1), 3-8.

Giovannoni, G., Butzkueven, H., Dhib-Jalbut, S., Hobart, J., Kobelt, G., Pepper, G. ve ark. (2016). Brain health: time matters in multiple sclerosis. Mult Scler Relat Disord, 9, S5S48. https://doi.org/10.1016/j.msard.2016.07.003

Green, E., Huynh, A., Broussard, L., Zunker, B., Matthews, J., Hilton, C. L. ve ark. (2019). Systematic review of yoga and balance: effect on adults with neuromuscular impairment. Am J Occup Ther, 73(1), 7301205150p1-7301205150p11. https://doi.org/10.5014/ajot.2019.028944

Hyarat, S. Y., Subih, M., Rayan, A., Salami, I., \& Harb, A. (2019). Health related quality of life among patients with multiple sclerosis: the role of psychosocial adjustment to illness. Arch Psychiatr Nurs, 33(1), 11-16. https://doi.org/10.1016/j.apnu.2018.08.006

Kalb, R., Brown, T. R., Coote, S., Costello, K., Dalgas, U., Garmon, E. ve ark. (2020). Exercise and lifestyle physical activity recommendations for people with multiple sclerosis throughout the disease course. Mult Scler J, 26(12), 14591469. https://doi.org/10.1177/1352458520915629

Kidd, T., Carey, N., Mold, F., Westwood, S., Miklaucich, M., Konstantara, E. ve ark. (2017). A systematic review of the effectiveness of self-management interventions in people with multiple sclerosis at improving depression, anxiety and quality of life. PLoS One, 12(10), e0185931. https://doi.org/10.1371/journal.pone.0185931

Kos, D., Duportail, M., Meirte, J., Meeus, M., D'hooghe, M. B., Nagels, G. ve ark. (2016). The effectiveness of a selfmanagement occupational therapy intervention on activity performance in individuals with multiple sclerosis-related fatigue: a randomized-controlled trial. Int J Rehabil Res, 39(3),

255-262. https://doi.org/10.1097/MRR.0000000000000178

Law, M. C., Baptiste, S., Carswell, A., McColl, M. A., Polatajko, H., \& Pollock, N. (1998). Canadian Occupational Performance Measure: COPM. CAOT Publ. ACE.

O'Loughlin, E., Hourihan, S., Chataway, J., Playford, E. D., \& Riazi, A. (2017). The experience of transitioning from relapsing remitting to secondary progressive multiple sclerosis: views of patients and health professionals. Disabil Rehabil, $\quad 39(18), \quad 1821-1828$. https://doi.org/10.1080/09638288.2016.1211760

Packer, T. L. (1995). Managing fatigue: a six-week course for energy conservation. Therapy Skill Builders. Tuscon, Ariz.

Patel, S., SirDeshpande, P., Desai, R., Desai, N., Mistry, H., Patel, N. ve ark. (2019). Thirty-day readmissions in multiple sclerosis: An age and gender-based US national retrospective analysis. Mult Scler Relat Disord, 31, 41-50. https://doi.org/10.1016/j.msard.2019.03.012

Quinn, É., \& Hynes, S. M. (2020). Occupational therapy interventions for multiple sclerosis: A scoping review. Scand J Occup Ther, 28(5), 1-16. https://doi.org/10.1080/11038128.2020.1786160

Salomè, A., Sasso D'Elia, T., Franchini, G., Santilli, V., \& Paolucci, T. (2019). Occupational therapy in fatigue management in multiple sclerosis: an umbrella review. Mult Scler Int, 2019, Article ID 2027947, 7 pages. https://doi.org/10.1155/2019/2027947

Torpil, B., Ekici-Çağlar, G., \& Bumin, G. (2018). Reliability and validity of the Canadian Occupational Performance Measure 
in people with multiple sclerosis. J Exerc Ther Rehabil, 5(2), 68.

van den Akker, L. E., Beckerman, H., Collette, E. H., Eijssen, I. C. J. M., Dekker, J., \& de Groot, V. (2016). Effectiveness of cognitive behavioral therapy for the treatment of fatigue in patients with multiple sclerosis: a systematic review and meta-analysis. J Psychosom Res, 90, $33-42$. https://doi.org/10.1016/j.jpsychores.2016.09.002

van Zanten, J. V., Douglas, M. R., \& Ntoumanis, N. (2021). Fatigue and fluctuations in physical and psychological wellbeing in people with multiple sclerosis: a longitudinal study. Mult Scler Relat Disord, 47, 102602. https://doi.org/10.1016/j.msard.2020.102602

Yu, C.-H., \& Mathiowetz, V. (2014). Systematic review of occupational therapy-related interventions for people with multiple sclerosis: Part 1. Activity and participation. Am J Occup Ther, 68(1), 27-32. https://doi.org/10.5014/ajot.2014.008672 